\title{
Androgen Antagonist APC-100
}

National Cancer Institute

\section{Source}

National Cancer Institute. Androgen Antagonist APC-100. NCI Thesaurus. Code C98290.

An orally available, vitamin E derivative and androgen receptor (AR) antag onist with potential anti-oxidant, chemopreventative and antineoplastic activity. APC-100 binds to ARs in target tissues thereby inhibiting androgen-induced receptor activation and facilitating the formation of inactive complexes that cannot be translocated to the nucleus. By inhibiting the formation of the complex between androgen activated AR- and the AP1 transcription factor JunD, the expression of androgen-responsive genes are blocked. One of such gene is spermidine/spermine N1-acetyl transferase gene (SSAT) that is responsible for the breakdown of polyamines, which are produced in high levels by prostatic epithelial cells, into reactive oxygen species (ROS) that cause cellular damage. APC-100 may ultimately lead to an inhibition of growth in both AR-dependent and ARindependent prostate tumor cells. 